\title{
Impacts of a nuclear war in South Asia on soybean and maize production in the Midwest United States
}

\author{
Mutlu Özdoğan • Alan Robock • \\ Christopher J. Kucharik
}

Received: 26 August 2011 / Accepted: 4 June 2012 / Published online: 22 June 2012

(C) Springer Science+Business Media B.V. 2012

\begin{abstract}
Crop production would decline in the Midwestern United States from climate change following a regional nuclear conflict between India and Pakistan. Using Agro-IBIS, a dynamic agroecosystem model, we simulated the response of maize and soybeans to cooler, drier, and darker conditions from war-related smoke. We combined observed climate conditions for the states of Iowa, Illinois, Indiana, and Missouri with output from a general circulation climate model simulation that injected $5 \mathrm{Tg}$ of elemental carbon into the upper troposphere. Both maize and soybeans showed notable yield reductions for a decade after the event. Maize yields declined 10-40 \% while soybean yields dropped 2-20\%. Temporal variation in magnitude of yield for both crops generally followed the variation in climatic anomalies, with the greatest decline in the 5 years following the $5 \mathrm{Tg}$ event and then less, but still substantial yield decline, for the rest of the decade. Yield reduction for both crops was linked to changes in growing period duration and, less markedly, to reduced precipitation and altered maximum daily temperature during the growing season. The seasonal average of daily maximum temperature anomalies, combined with precipitation and radiation changes, had a quadratic relationship to yield differences; small $\left(0{ }^{\circ} \mathrm{C}\right)$ and large $\left(-3{ }^{\circ} \mathrm{C}\right)$ maximum temperature anomalies combined with other changes led to increased yield loss, but medium
\end{abstract}

M. Özdoğan ( $ه)$

Center for Sustainability and the Global Environment \& Department of Forest and Wildlife Ecology, University of Wisconsin-Madison, Madison, WI, USA

e-mail: ozdogan@wisc.edu

A. Robock

Department of Environmental Sciences, Rutgers University, New Brunswick, NJ, USA

email: robock@envsci.rutgers.edu

C. J. Kucharik

Center for Sustainability and the Global Environment \& Department of Agronomy,

University of Wisconsin-Madison, Madison, WI, USA

email: kucharik@wisc.edu 
changes $\left(-1^{\circ} \mathrm{C}\right)$ had small to neutral effects on yield. The exact timing of the temperature changes during the various crop growth phases also had an important effect.

\section{Introduction}

In the event of nuclear war, targets in cities and industrial areas would emit light-absorbing particles (i.e., black carbon, soot, or elemental carbon) into the atmosphere from fires. By blocking sunlight, elemental carbon would cause significant changes to solar radiation, temperature, and precipitation patterns. For example, evidence suggests "volcanic winters" and "years without summers" follow large volcanic eruptions such as Tambora in 1815 . Under these conditions, unusual mid- to late-summer cooling and frost have caused crop failure over millions of hectares of cultivated areas (Post 1977; Stommel and Stommel 1979; Harington 1992; Oppenheimer 2003). Less known, however, is whether similar crop failure might be caused by a regional nuclear conflict.

Vulnerability of agricultural systems to nuclear war was recognized in the 1980s. Ehrlich et al. (1983) reported subfreezing temperatures, low light levels and high doses of UV light as drivers of large-scale decline in crop productivity in the Northern Hemisphere following a large-scale nuclear war. Harwell and Cropper (1985), investigated the agricultural effects of a large-scale nuclear war using both an empirical approach and simple crop growth models and concluded that significant reduction in crop yields and associated production could occur, primarily caused by shortening of the growing season and reduction of thermal time needed by crops to reach physiological maturity. Sinclair (1986) simulated potential soybean production following a nuclear winter in Midwestern U.S. and showed that temperature reductions of $2-4{ }^{\circ} \mathrm{C}$ throughout the growing season could substantially reduce yields.

The purpose of this research is to quantify changes in the Midwestern U.S. from a regional nuclear conflict. More specifically, we used temperature, precipitation, and solar radiation anomalies produced by a modern global climate model under a regional nuclear war scenario in a sophisticated dynamic crop growth model to assess the magnitude and timing of changes in maize and soybean production in four locations. Additionally, we investigated the causes of yield changes with an eye toward adaptation options.

\section{Methodology}

We simulated maize and soybean yields affected by a hypothetical nuclear conflict between India and Pakistan in which $5 \mathrm{Tg}$ (five million metric tons) of elemental carbon is released into the upper troposphere. Atmospheric circulation and associated changes in temperature, precipitation, and solar radiation were simulated by ModelE, a general circulation model (GCM) (Schmidt et al. 2006) from the Goddard Institute for Space Studies (Robock et al. 2007). For more details on the climate model results, please see Xia and Robock (2012).

\subsection{The Agro-IBIS model}

We used a comprehensive terrestrial ecosystem model called Agro-IBIS equipped with process-based models of corn, soybeans, spring and winter wheat, and management choices, simulating both managed and natural ecosystems (Foley et al. 1996; Kucharik et al. 2000; Kucharik 2003; Kucharik and Twine 2007). Agro-IBIS simulations of carbon, nitrogen, energy and water cycling variables have been extensively validated in optimally fertilized 
and unfertilized corn agroecosystems in southern Wisconsin from 1995 to 2000 (Kucharik and Brye 2003). Regional-scale calibrations and validations for mean corn and soybean yields were also made in the Upper Mississippi drainage basin (Donner and Kucharik 2003) for the 1985-1994 period. More recent work has compared simulated crop biophysical and phenological development with satellite data (Twine and Kucharik 2008), and Sacks and Kucharik (2011) analyzed the impact of trends in crop management and phenology on yields, evapotranspiration (ET), and energy balance across the Midwest.

\subsection{Perturbation of contemporary climate data}

To generate a new daily dataset incorporating effects of a nuclear war, the daily observed values of minimum and maximum temperature, precipitation, and solar radiation were uniformly perturbed using monthly anomalies of these quantities for 10 consecutive years. For the temperature variables and solar radiation, monthly anomalies from Robock et al. (2007) were added to daily quantities uniformly over each month. The temperature anomalies were weighted; $80 \%$ of the anomaly was added to the maximum and only $20 \%$ to the minimum temperature, following Robock (1988) and (1991). For precipitation, we calculated total observed rainfall for the month in question, divided the monthly anomaly by the observed monthly total, then reduced the precipitation on days that it occurred by that fraction for each day. While evidence suggests that increases in the fraction of diffuse sunlight can impact crop growth (Spitters 1986), these increases were not considered. Neither did we take into account the very large losses of stratospheric ozone and associated increase in ultraviolet light following a nuclear conflict (Mills et al. 2008).

Preliminary analysis indicated that reductions or increases in yields are significantly impacted by the weather conditions of the control run. Therefore we generated a synthetic control climate data set for 300 years by randomly selecting 10 individual years, 30 times, from the original 29-year (1979-2007) daily time series, assuming no year-to-year autocorrelation. This 300 -year data set provided 30 realizations of each year of the 10 -year segments so that the distribution of yield associated with year-to-year variations in climate for each analysis year could be examined.

\subsection{Experiments}

We conducted two experiments using both observed and perturbed climate data. For each, Agro-IBIS was run for 300 years using twelve $0.25^{\circ} \times 0.25^{\circ}$ grid cells centered at four locations in the Midwest (Table 1). The sites are located along an east to west summer precipitation gradient, but with similar mean annual temperature. We modeled the yield of maize and soybeans, which are the most abundant crop types grown in the Midwest, while keeping ambient atmospheric $\mathrm{CO}_{2}$ concentrations consistent with the year 2000 (370 ppm). In each case, all management practices including nitrogen-based fertilizer use $(150 \mathrm{~kg} / \mathrm{ha}$ for maize,

Table 1 Location of sites used in this analysis

\begin{tabular}{|c|c|c|c|}
\hline Site & Location & Latitude/longitude & Description \\
\hline IA & Southwest Iowa & $42.0^{\circ} \mathrm{N}-95.0^{\circ} \mathrm{W}$ & mixture of cropland, prairie and savanna \\
\hline IL & Central Illinois & $40.0^{\circ} \mathrm{N}-89.0^{\circ} \mathrm{W}$ & mixture of cropland and prairie \\
\hline IN & Northern Indiana & $41.0^{\circ} \mathrm{N}-87.0^{\circ} \mathrm{W}$ & drift plains, croplands, and sandy areas \\
\hline MO & N Central Missouri & $40.5^{\circ} \mathrm{N}-92.0^{\circ} \mathrm{W}$ & mixture of forests and croplands \\
\hline
\end{tabular}


$25 \mathrm{~kg} /$ ha for soybeans (NASS 2011)) and irrigation (if necessary) were allowed. The planting date was prognostically determined by the model. The other phenological stages (e.g., emergence, flowering, maturity) were driven by growing degree day (GDD) accumulations. All runs were initiated from soil $\mathrm{C}$ and $\mathrm{N}$ conditions determined by a spin-up procedure (Kucharik et al. 2000). Thus the coupled C-N cycle contributed a realistic amount of $\mathrm{N}$ for uptake through $\mathrm{N}$ mineralization. The irrigation module was activated automatically - and mostly in more arid locations. No adaptation strategies including shifting of planting and harvesting dates or different varieties were tested here, but we discuss below how effective these might be (e.g., Sacks and Kucharik 2011).

To assess the performance of Agro-IBIS we compared simulated yields to reported production in each location extracted from the National Agricultural Statistics Service (NASS) database http:/quickstats.nass.usda.gov/?source_desc=CENSUS for the county that the simulation site was located. Ten years of data (1996-2005) were extracted from the database and compared to the modeled yields simulated with daily climate observations for the same period.

To assess changes in crop yields, we calculated the difference in predicted quantities with and without nuclear perturbation in the form of relative change from the control scenario using

$$
\text { yield change }(\%)=\frac{\text { nuclear }- \text { control }}{\text { control }} * 100 \text {. }
$$

In this formulation, negative values indicate reduction in yields.

\section{Results}

\subsection{Expected changes in climatic variables}

In the decade following the $5 \mathrm{Tg}$ event, all forcing variables depict negative anomalies, indicating significant drying and cooling of the lower atmosphere, as well as a reduction in solar radiation in the four sites (Fig. 1). Temperature displays more negative than positive anomalies, indicating significant cooling through the decade. Solar radiation has a large drop in the first year, recovers gradually through the study period, but remains negative partly because of strong absorption of sunlight by black smoke even after 10 years (Robock et al. 2007). The precipitation anomaly varies the most across sites, followed by temperature and radiation, as indicated by the large spread around the mean value. Robock et al. (2007) showed that when averaged globally and annually, the temperature anomaly reduces to $-0.5{ }^{\circ} \mathrm{C}$ in year 10 , but anomalies in the Midwest do not exhibit this behavior; even in year 10, the anomalies are noisy, and very cool summers still can occur.

\subsection{Performance of the crop model}

There is considerable agreement between modeled and observed yields (Fig. 2). Across all sites, maize yield ranges from 8 to 12 tha both under simulated and observed conditions. Agro-IBIS predictions for maize are generally higher than observed values. The mismatch is least ( $1 \mathrm{t} / \mathrm{ha}$ difference) in the IA site and most in MO (4t/ha difference). For soybeans, predictions are well within the range of reported mean values across all sites but in contrast to maize simulations, reported yields are higher in two of four cases. The spread of modeled yields is also larger than observed variation in both crops. But for all locations and crops, the results are within error bars of both modeled and observed quantities. 

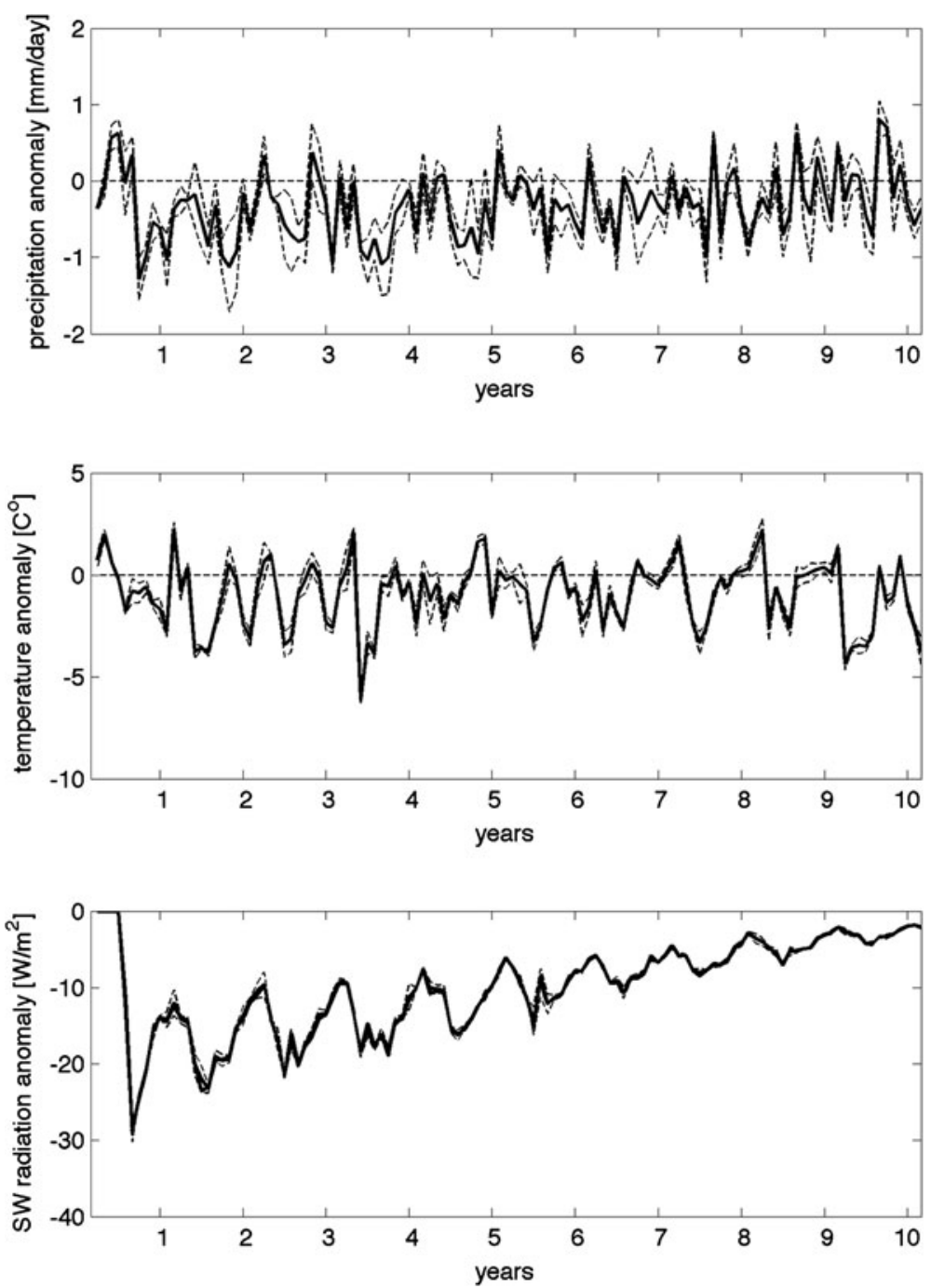

Fig. 1 Predicted temporal changes in precipitation, air temperature, and net shortwave radiation following a $5 \mathrm{Tg}$ nuclear conflict. The thick black line represents the mean anomaly across the four sites while the broken line around the mean is the standard deviation across all sites. Data from Robock et al. (2007)

\subsection{Climatic drivers of simulated yields}

Both crops respond linearly and positively to growing season precipitation availability (Figs. 3 and 4). There is a three-fold increase in yields of both crops over a $400 \mathrm{~mm}$ $(100-500 \mathrm{~mm})$ precipitation range. In the case of seasonal maximum temperature, both yields respond negatively to increases in maximum temperature, although soybeans appear to have greater sensitivity than maize. The relationship between minimum temperature and yields is much weaker or non-existent. Available insolation is moderately correlated with yields although the correlation is better with yield of soybeans than maize yields. One reason for the solar radiation effect may be that it drives maximum temperatures during the day; as 


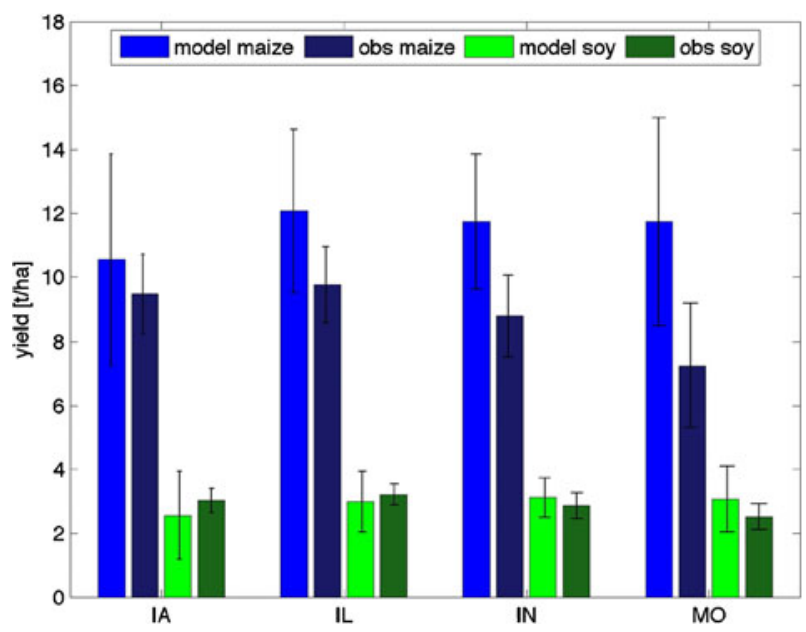

Fig. 2 Comparison of modeled and reported mean yields of maize and soybean in locations considered in this study. The error bar represents the variation in the form of one standard deviation across years. The reported yields are averaged over 10 years (1996-2005)

radiation increases, maximum temperatures rise, leading crops to accelerate their GDD accumulation quicker, with fewer calendar days to accumulate biomass. Also, increased radiation associated with increases in maximum temperature and decreases in precipitation may lead to greater evapotranspiration, causing soil moisture stress to increase.
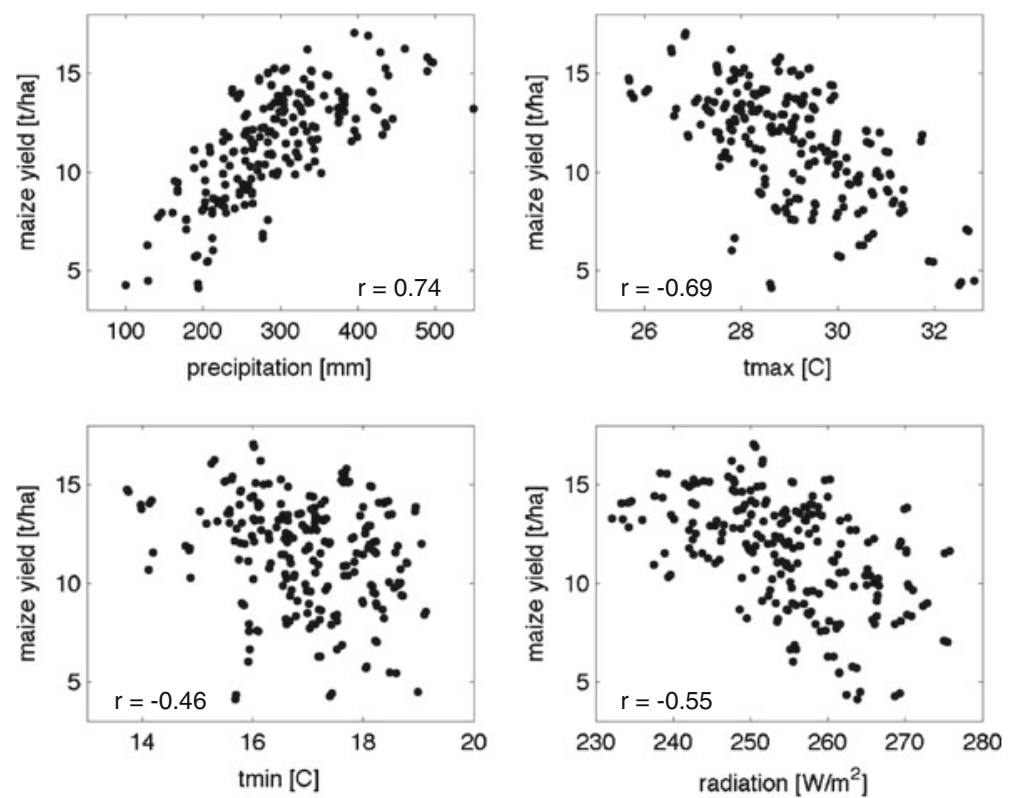

Fig. 3 Climatic controls of modeled maize yields in Midwestern U.S. under nuclear war conditions. Data are from all sites. Climate data represent the average growing season conditions between June and August. For precipitation, the growing season sum is shown and for temperature and radiation variables, the average is shown. The Pearson correlation coefficient (r) is provided for reference 

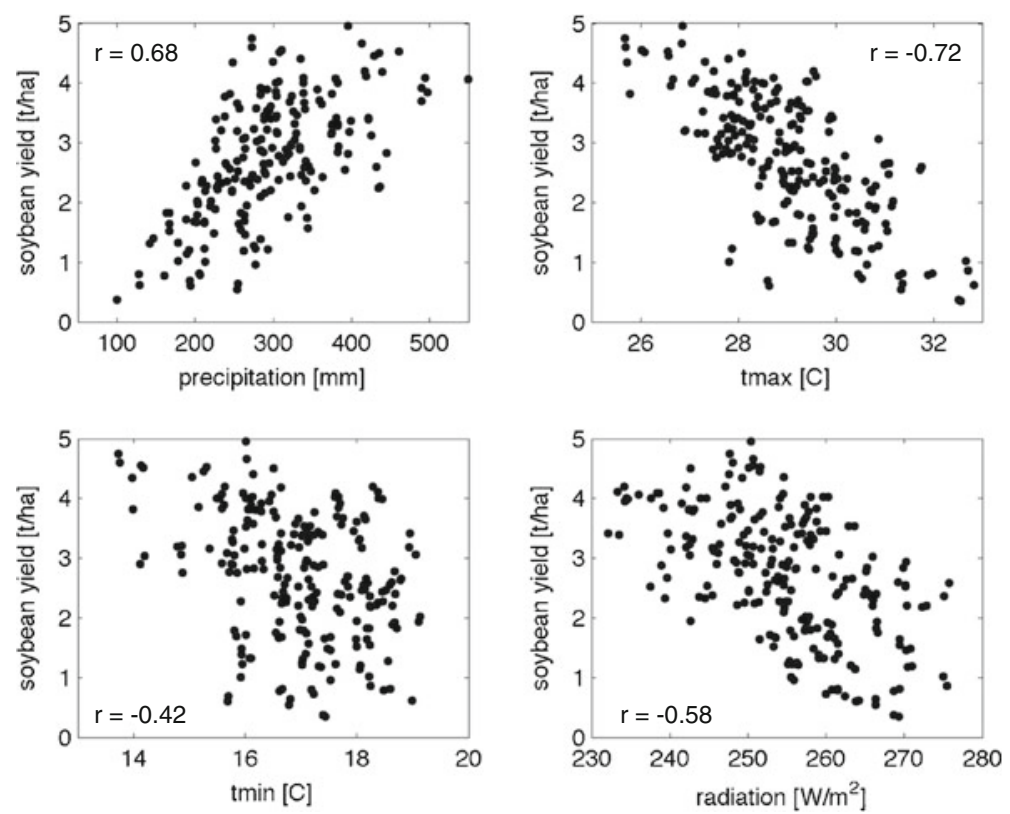

Fig. 4 Climatic controls of modeled soybean yields in Midwestern U.S. under nuclear war conditions. Data are from all sites. Climate data represent the average growing season conditions from June through August. For precipitation, the growing season sum is shown and for temperature and radiation variables, the average is shown. The Pearson correlation coefficient (r) is provided for reference

To test effects of different forcing variables on maize under the nuclear scenario, we ran a multiple linear regression model to predict yields. When all forcing variables were included, they explained about $44 \%$ of the variability; precipitation and maximum temperature were statistically significant while minimum temperature and radiation were not. In the full model, precipitation had significant positive effect and tmax had significant negative effect. For each $100 \mathrm{~mm}$ increase in precipitation, maize yields would be expected to rise $1.2 \mathrm{t} / \mathrm{ha}$. For each degree increase in maximum temperature, yields would be expected to fall $0.45 \mathrm{t} / \mathrm{ha}$.

For soybean, the full model explained roughly $58 \%$ of the variability; precipitation, tmax, and radiation were significant while tmin was not. Precipitation had significant positive effect, while all other forcing variables affected yield negatively. The effect of minimum temperature was negative but not significant. In the full model, each $100 \mathrm{~mm}$ increase in precipitation would raise soybean yield $1.2 \mathrm{t} / \mathrm{ha}$; each $100 \mathrm{~mm}$ increase in precipitation would raise soybean yield $0.4 \mathrm{t} / \mathrm{ha}$. For each Celsius degree increase in tmax, soybean yield would decrease by $0.29 \mathrm{t} / \mathrm{ha}$.

\subsection{Expected yield changes under the $5 \mathrm{Tg}$ scenario}

The sensitivity of the ecological model to variations in weather affects the results of the nuclear run because it is weather conditions through which yield effects of a nuclear war are assessed. Therefore we present most yield change results as a probability distribution rather than a single value (Figs. 5 and 6). The first year in each model result was unimportant because the hypothetical war did not start until mid-May in year one.

For maize, the relative changes are normally distributed with a mean around $-10 \%$ and equal magnitude of spread when averaged across all locations. The mean change ranges 

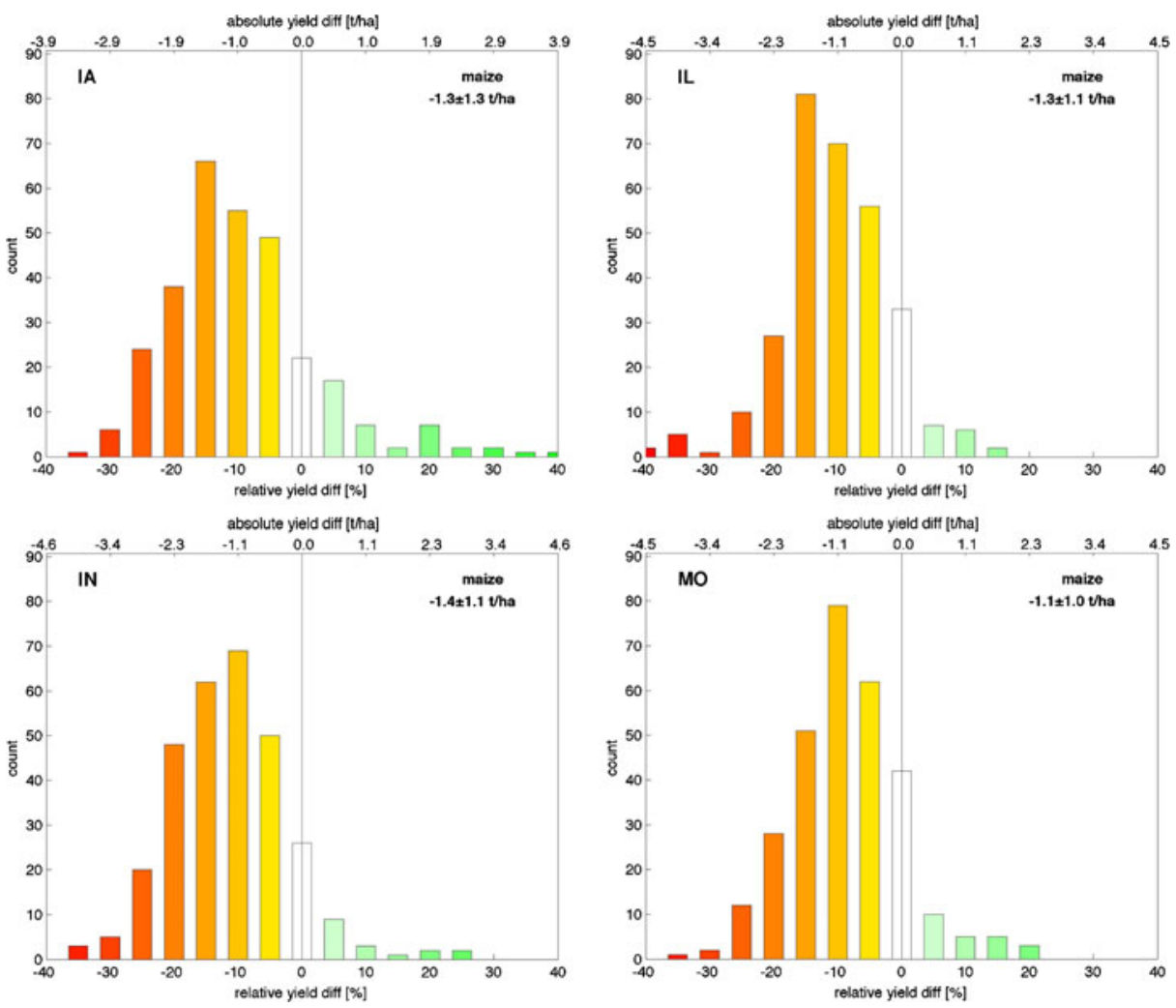

Fig. 5 Histogram distribution of relative and absolute changes in modeled maize yields in four locations following the $5 \mathrm{Tg}$ event. Small to nil yield changes are shown in white. Gradation of yellow to red colors depict reductions in yields while the hues of green indicate increases. The mean and variation of expected yield changes in absolute terms ( $\mathrm{t} / \mathrm{ha}$ ) are also given

from $-7 \%$ at IL to $<-12 \%$ at the IA site with similar variation in all sites. The $5 \mathrm{Tg}$ event occasionally increases maize yields a small amount in all locations but the likelihood of this is fairly small; when averaged over all locations, the probability of yield increase is $<15 \%$, using the normal probability density function. In each case, the maximum yield change could be as low as $-50 \%$ but the likelihood of this extreme decline is low.

Relative changes in soybean yields also show a normal distribution but with greater variable mean value, ranging from a $6 \%$ decline in IL to more than $12 \%$ in MO. Variability in each location is also much higher for soybeans than for maize yields, exceeding $20 \%$ in one location. Like maize, soybean yields are predicted to decline following the $5 \mathrm{Tg}$ event; this result is reflected in the bulk of the distribution being negative. However, more results indicate reduction in maize than in soybeans.

Of interest is how yield change results would evolve over time following the $5 \mathrm{Tg}$ event. Figures 7 and 8 display predicted relative changes in maize and soybean yields. For maize, mean relative change is predicted to be more than a $20 \%$ decline in year five, with all years showing production losses through year seven. Productivity then recovers and begins to vary in years $8-10$ by $\sim 5-10 \%$. The decline could reach $40 \%$ on one occasion (year 5 at the IL site) while increase could be $10 \%$ at year 10 (Fig. 7) depending upon which decade in the 30 years is chosen as the unperturbed state. In general, the number of years of decline is 

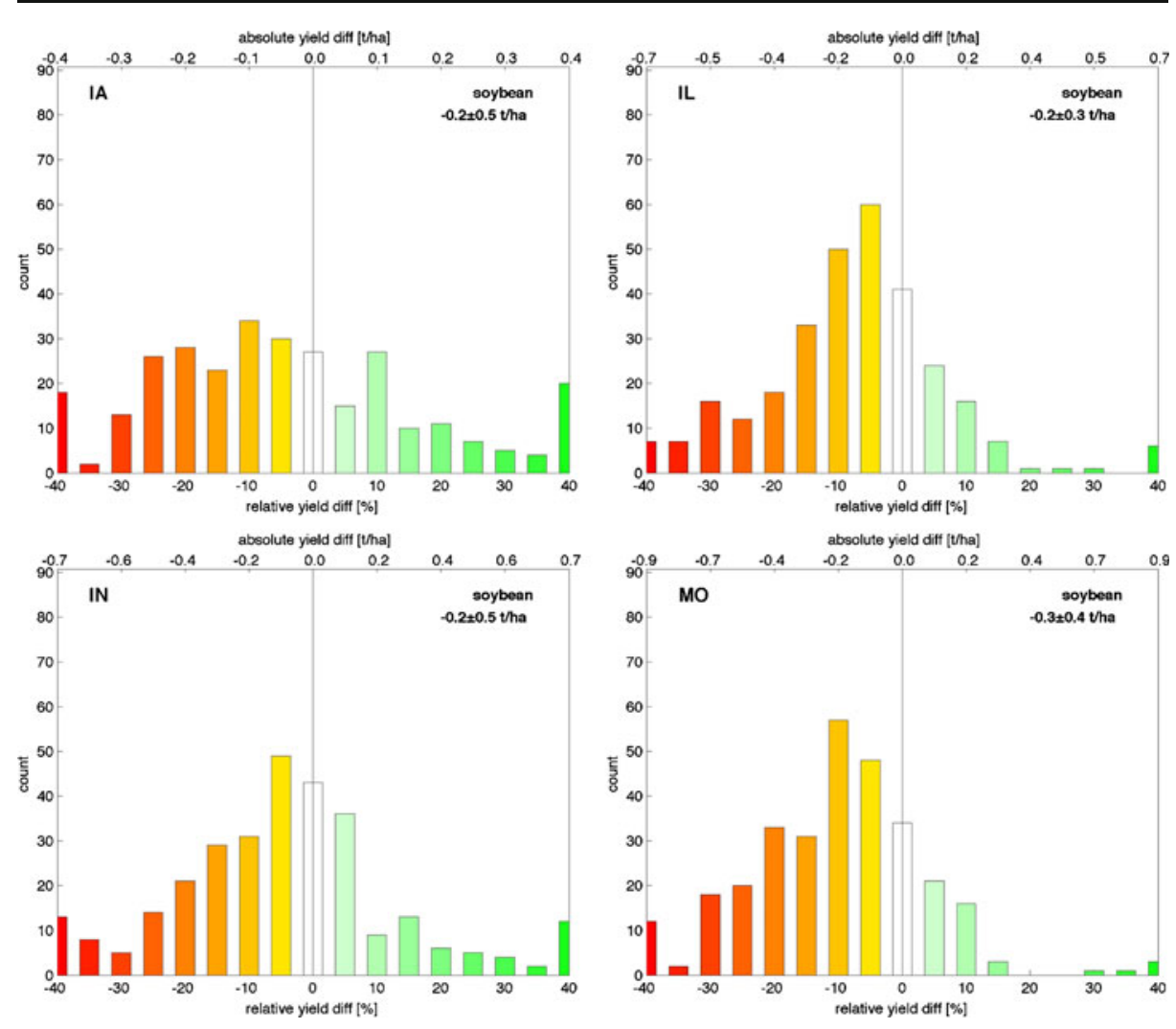

Fig. 6 Histogram distribution of relative and absolute changes in modeled soybean yields in four locations following the $5 \mathrm{Tg}$ event. Small to nil yield changes are shown in white. Gradation of yellow to red colors depict reductions in yields while the green hues indicate increases. Also provided are the mean and variation of expected yield changes in absolute terms ( $\mathrm{t} / \mathrm{ha})$

greater than the number of years of increase ( 8 of 10 vs. 2 of 10). Even for years with significant mean increase in yield (e.g., year 10), some experiments suggest a decline. In fact, every year examined has one or more negative changes. Moreover, the temporal profile of yield change across 10 years is curvilinear, having little or no decline early in the decade, greatest decline in the middle, and a potential increase at the end.

Soybean yields show similar trends but with much greater variation. Mean soybean yields are expected to decline by as much as $20 \%$ in the mid-decade although the beginning and end of the decade could see significant increases in yields (20\% on average). While this is true for the mean change, each year has at least one negative change.

\subsection{What are the drivers of yield change in the nuclear scenario?}

We examined the relationship between changes in climatic quantities and the difference in yields between the control and nuclear runs for both crops. With maize, there is a strong quasilinear correlation between precipitation and yield, where a large precipitation decline $(0-$ $50 \mathrm{~mm}$ /growing season) results in a 1-3 t/ha decline in yield while increases in precipitation lead to neutral or positive changes. Differences in both maximum and minimum temperatures 

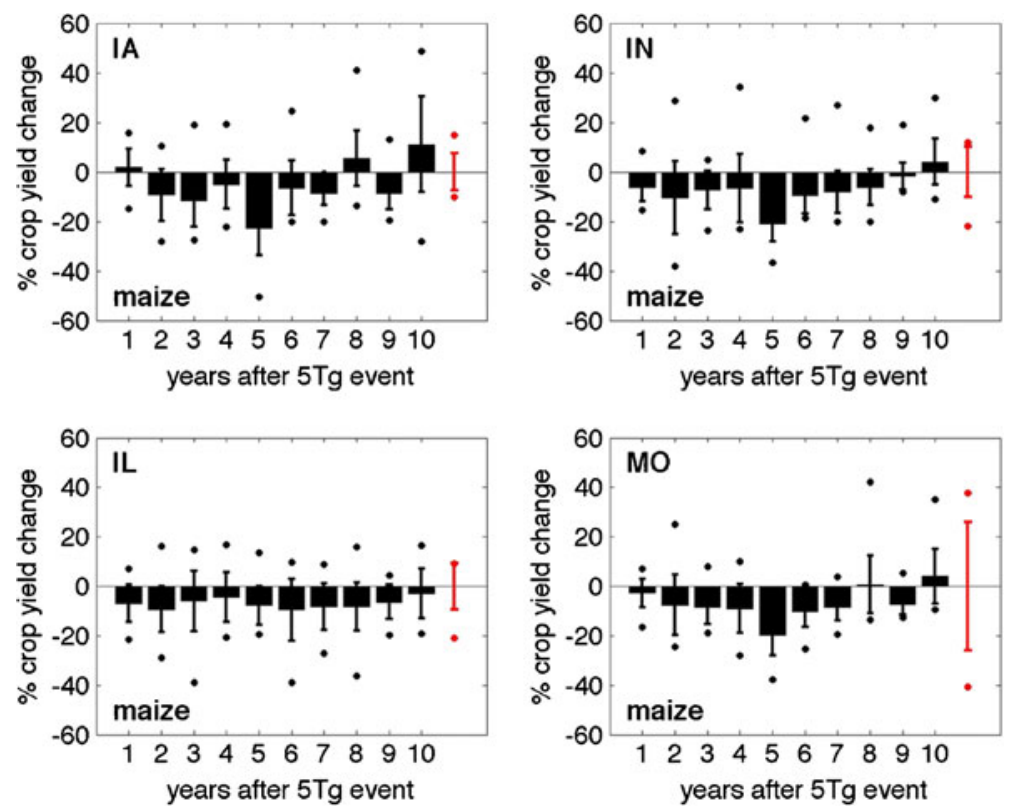

Fig. 7 Mean relative changes in maize yields across four sites over a decade following the 5 Tg nuclear event. Negative values indicate a decrease from the control run. Each black bar represents the average of 30 realizations of the model run for a given year while the whiskers indicate \pm one standard deviation across experiments. The minimum and maximum yield changes across 30 model runs are shown as black dots. A missing black dot means it was outside of the range of Y-axis limits. The natural variation of maize yield over a 10-year period in each location is shown in red. The mean of natural variation is set to zero and the spread is given in the form of percent deviation from this natural mean

averaged over the growing season have non-linear correlations with yield changes, suggesting a larger decline when these quantities exhibit extreme negative or positive changes, but smaller yield decreases are expected when changes are small. Changes in available radiation following a nuclear event have an expected relationship with yields where large decreases in insolation also lead to large decreases in yield. The values for no change in precipitation or temperature also do not cross the zero line. This is partially because the synergistic impact of all the simultaneous perturbations (precipitation+temperature+radiation) contribute to the yield reduction.

Soybean yield differences have a strong but non-linear response to precipitation; any decline in rainfall leads to a decline in yields but increases in precipitation suggest small yield increases. The response of soybeans to both minimum and maximum temperatures are harder to interpret; they suggest increases in both quantities (rather than a decrease caused by a regional nuclear war) affect yields more. The radiation response of soybean yields is strongly non-linear; the greatest yield decline occurs when insolation is reduced by the average amounts. There is little or no yield effect when large or small decreases occur.

The temporal variation in yield over 10 years as shown in Figs. 7 and 8 does not conform to modeled climatic anomalies as expected. While the greatest precipitation, temperature, and radiation reductions occur in years 2-5, the yield response to these anomalies is highest in year five for all sites and crops. To further investigate this pattern, we also analyzed the relationship between yield difference and the maximum temperature and precipitation difference by individual years. Interestingly, the anomalous fifth year decline appears to 

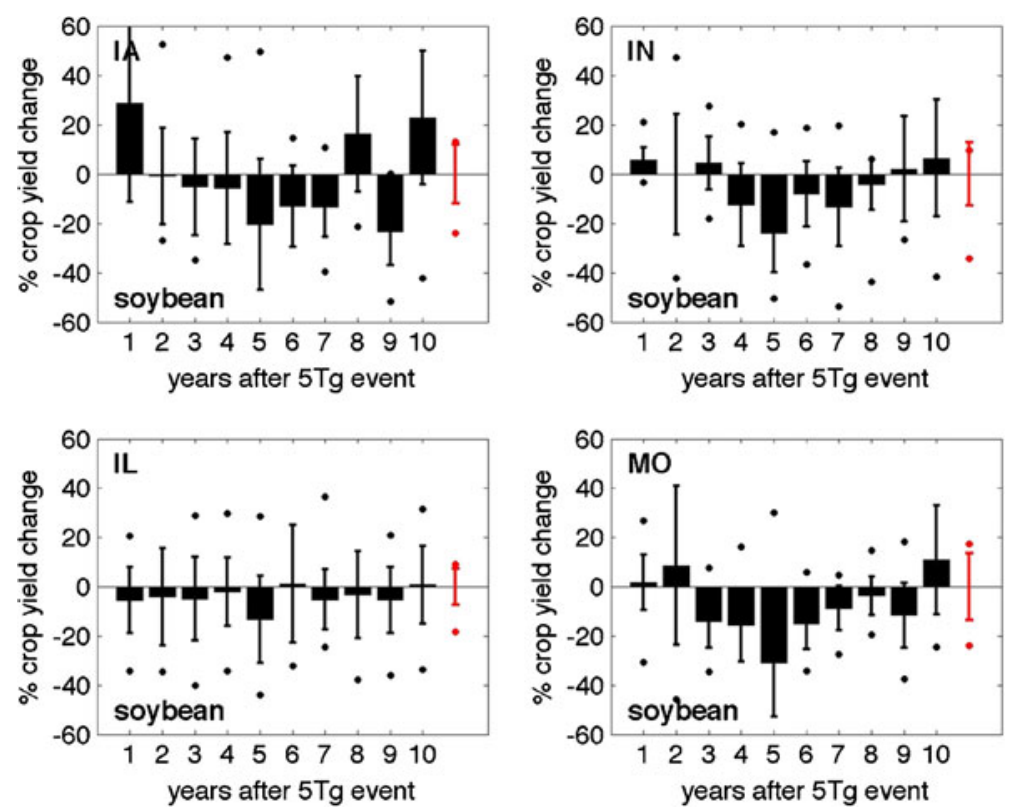

Fig. 8 Mean relative changes in soybean yields across four sites over a decade following a $5 \mathrm{Tg}$ nuclear event. Negative values indicate a decrease from the control run. Each black bar represents the average of 30 realizations of the model run for a given year while the whiskers indicate \pm one standard deviation across experiments. The minimum and maximum yield changes across 30 model runs are shown as black dots. A missing black dot means it was outside of the range of Y-axis limits. The natural variation of soybean yield over a 10 year period in each location is shown in red. The mean of natural variation is set to zero and the spread is given in the form of percent deviation from this natural mean

be caused by temperature increase. That is, both crops experience the largest drop in yields when maximum temperature increases. In fact, when the temperature anomaly in Fig. 1 is averaged over the growing season on year five, the anomaly is positive. When applied to maximum temperature as required by the model, this anomalous increase in maximum temperatures negatively affects yields since there is a negative relationship between maximum temperatures and yields. For maize, the decline is smaller in years one, eight, and ten than in years two, three, and four. On the other hand, soybean yields are less sensitive to large reductions in maximum temperatures as exhibited by years one, two, four, eight, and ten. When maximum temperatures are increased, soybean yields also experience the largest reductions as in year five following the event.

Yield changes due to precipitation are less apparent in the anomalous year five. Thus, a year with a large reduction in rainfall corresponds to the largest reduction in yield for both crops. However, as the precipitation anomaly switches from negative to positive, yields respond positively as in year ten, although it is difficult to tease apart the combined effects of temperature and precipitation as drivers of yield change.

Another interesting question concerns changes in planting and harvest dates. These changes are important for two reasons. First, crop yield is partially determined by the length of the growing period. Thus changes to the length of the period will affect production (Kucharik 2006; Lobell and Field 2007; Sacks and Kucharik 2011). Second, the crop growth simulations were conducted under a zero adaptation assumption. Given the wide range of cultivars that span short to long growing seasons where corn and soybeans are planted, one 
adaptation strategy would be to consider subtle climate changes and offer appropriate varieties to farmers for their particular region.

The nuclear event is always accompanied either with no change or later planting for both crops and the magnitude of changes in the planting date has a non-linear impact on yield decline: up to a 10-day delay in sowing brings little or no change, but beyond 10 days yield reduction accelerates for both crops. The relationship between changes in yields and changes in the length of the growing period suggest that maize yields experience little or no change when the length of the growing period remains the same or extended but maize yields drop precipitously as the growing period is progressively shortened. This finding also applies to soybeans, although the rate of yield decline increases faster than maize yields as the number of days in the growing period is reduced.

\section{Discussion and conclusions}

Our results suggest that temperature and solar radiation perturbations in midlatitude locations play a greater role than precipitation in reducing yields. Based on observational evidence, recent work by Kucharik $(2006,2008)$ has shown that increases in the growing season length and the timing of sowing and harvest dates due to increases in temperatures and changes in agricultural technology (e.g., improved hybrids) have contributed to increased corn and soybean yields. In our study, cooler conditions associated with a nuclear conflict, which may shorten the frost-free growing season, could lead to fewer calendar days for crops to intercept radiation and perform photosynthesis. In contrast, should temperatures increase with nuclear conflict generated short-term climate change during the growing season, an accelerated rate of growing degree day accumulation could contribute to crops progressing through their phenological stages more quickly, with fewer calendar days to accumulate biomass. Thus, temperature changes can create a myriad of feedbacks affecting yield; some could be positive, and some negative, but the time of year these temperature anomalies occur is critical. Our results indicate that average lower temperatures in spring associated with the nuclear conflict could delay planting, but depending on the course of temperature accumulation during the rest of the season, crops could achieve physiological maturity at an earlier or later date. While later planting could be an adaptation option to limit this temperature effect, one needs to consider the increased risk of encountering killing temperatures before physiological maturity occurs (Sacks and Kucharik 2011). Our analysis emphasizes the impact of cooler spring conditions on delayed planting, a shorter growing period and lower yields.

The potential for adapting maize-soybean systems to climate change is well documented (e.g., Lobell et al. 2008; Ainsworth and Ort 2010). These strategies may include development of new technologies that permit crops to be more drought- and cold-resistant or have different carbon allocation strategies (Lopes et al. 2011). For example, the trend toward earlier corn planting in the U.S. (e.g., Kucharik 2006) is partially supported by development of temperature-activated polymers applied to seeds. Moreover, planting densities have increased, and harvest index has also increased through the development of stay-green hybrids (Tollenaar and Lee 2010). Where water is limited, irrigation may be a solution. The Midwest is not generally considered a water-limited region so a small investment in irrigation infrastructure could alleviate the reduced precipitation expected as a result of a regional nuclear war.

While GCM output suggests that the largest precipitation, temperature, and radiation changes occur in years $2-5$, the yield response to these anomalies is greatest in year five for 
all sites and crops. However, given that the GCM results used in this study reflect only one scenario and one climate model, the effects could be coincidental, as a regional conflict could bring about considerable variability in worldwide climate conditions. Thus the results presented here are indicative of the amplitude of effects that could result in the Midwest or elsewhere. Yet the Robock et al. (2007) study involved three runs whose mean is used here, so variability may already be reduced: it is possible that for any individual realization there might be greater extremes.

Several reasons can explain the differences between observed and Agro-IBIS predicted yields. First, we used a 10 year (1995-2006) average of USDA yield data. However, summer crop yields are generally increasing at a rate of about $1.3 \%$ per year (NASS). Agro-IBIS is calibrated to simulate current (e.g., 2012) yields, so it is somewhat expected that yields are higher than the longer-term observed averages. Since the USDA yields are representative of $\sim 2000$ (mid point of 1995-2006), there are 12 years between that value of yield and the most current value simulated by Agro-IBIS (ca. 2011). With an average increase in yields of $1.3 \%$ per year, the current yields would be about $14 \%$ higher than the values on the graph for observed and that would close the gap between observed and simulated. The issue of declining model performance for corn as one goes from counties in IA, IL, IN to MO is partially explained by the fact that counties with higher number of harvested acres in the USDA data generally lead to a better comparison with Agro-IBIS (especially for corn) because averaging occurs over many more combinations of weather, soils, and management combinations (Kucharik 2003). In fact the MO site has the least area of planted acres of both crops of all sites. Therefore, this is not necessarily a model issue, but rather a quality of data issue when comparing results from a point simulation (or collection of points) to county averages.

It is possible to tune various parameters in Agro-IBIS to match observed yields perfectly but this may inadvertently lead to a model "over fitting". However, there is no guarantee that the model will agree better across all sites because fundamental issues that likely contribute to variation in yields from year to year as well as across sites will not be accounted for. So the parameter adjustment approach would not necessarily be simulating yield average values from about 10-15 years ago, especially considering that the current work is not about model fitting and calibration for the past, but about looking at potential yield responses for some point in time.

Our research suggests that both maize and soybeans may experience notable yield reductions in the event of a nuclear conflict beyond the natural variation of both crops. The United States is the world's largest producer and exporter of corn; the Midwest supplies $80 \%$ of this production. If yield declines as suggested here were to occur, overall production could be depressed for several years following the nuclear conflict, affecting both market conditions and livelihoods. While the economic impacts are not explored here, they are likely to be large, given the prominence of the contribution of corn and soybeans to domestic market needs for food, feed, and fuel as well as to agricultural exports.

Unlike global climate change caused by radiative forcing, the changes created by a nuclear conflict would have different duration: the radiative forcing from greenhouse gases are expected to persist for a century or more while that generated by a nuclear conflict is likely to last for only a decade (Toon et al. 2008). Nevertheless, the economic and societal consequences of yield changes resulting from this short-lived climatic alteration could eclipse the long-term changes from greenhouse gas emissions that allow ample time for development and application of a variety of adaptation strategies to mitigate yield losses. Therefore we conclude that the best way to limit the effects of a nuclear war on agriculture is to eliminate all nuclear weapons. 
Acknowledgments We thank Luke Oman for providing us with the climate model output for Midwestern U.S. This work is partially supported by the Switzerland Federal Department of Foreign Affairs, NSF grant ATM-0730452, and NOAA grant NA08OAR4310873. Authors are also indebted to Mr. George Allez for his meticulous editing to make the article more concise. Finally, the suggestions of three anonymous reviewers significantly improved this manuscript.

\section{References}

Ainsworth EA, Ort DR (2010) How do we improve crop production in a warming world? Plant Physiol 154:526-530

Donner SD, Kucharik CJ (2003) Evaluating the impacts of land management and climate variability on crop production and nitrate export across the Upper Mississippi Basin. Global Biogeochem Cycles 17(3):1085. doi:10.1029/2001GB001808

Ehrlich PR, Harte J, Harwell MA, Raven PH, Sagan C, Woodwell GM, Berry J, Ayensu ES, Ehrlich AH, Eisner T, Gould Sl, Grover HD, Herrera R, May RM, Mayr E, McKay CP, Mooney HA, Myers N, Pimentel D, Teal JM (1983) Long-term biological consequences of nuclear war. Science 222:1293-1300

Foley JA, Prentice IC, Ramunkutty N, Levis S, Pollard D, Sitch S, Haxeltine A (1996) An integrated biosphere model of land surface processes, terrestrial carbon balance and vegetation dynamics. Global Biogeochem Cycles 10:603-628

Harington CR (ed) (1992) The year without a summer? World climate in 1816. Canadian Museum of Nature, Ottawa, p 576

Harwell MA, Cropper WP (1985) Potential effects of nuclear war on agricultural productivity. In: Harwell MA, Hutchinson TC (eds) SCOPE 28 - environmental consequences of nuclear war volume II: ecological and agricultural effects. John Wiley and Sons, New York, pp 271-355

Kucharik CJ (2003) Evaluation of a process-based agro-ecosystem model (Agro-IBIS) across the U.S. cornbelt: simulations of the inter-annual variability in maize yield. Earth Interact 7:1-33

Kucharik CJ (2006) A multidecadal trend of earlier corn planting in the central U.S. Agron J 98:1544-1550

Kucharik CJ (2008) Contribution of planting date trends to increased maize yields in the central United States. Agron J 100:328-336. doi:10.2134/agronjn12007.0145

Kucharik CJ, Brye KR (2003) Integrated BIosphere Simulator (IBIS) yield and nitrate loss predictions for Wisconsin maize receiving varied amounts of nitrogen fertilizer. J Environ Qual 32:247-268

Kucharik CJ, Twine TE (2007) Residue, respiration, and residuals: evaluation of a dynamic agroecosystem model using eddy flux measurements and biometric data. Agric For Meteorol 146:134-158. doi:10.1016/ j.agrformet.2007.05.011

Kucharik CJ, Foley JA, Delire C, Fisher VA, Coe MT, Gower ST, Lenters J, Molling C, Norman JM, Ramankutty N (2000) Testing the performance of a dynamic global ecosystem model: water balance, carbon balance, and vegetation structure. Global Biogeochem Cycles 14:795-825

Lobell DB, Field CB (2007) Global scale climate-crop yield relationships and the impacts of recent warming. Environ Res Lett 2:014002

Lobell DB, Burke MB, Tebaldi C, Mastrandrea MD, Falcon WP, Naylor RL (2008) Prioritizing climate change adaptation needs for food security in 2030. Science 319:607-610

Lopes M, Araus JL, van Heerden PDR, Foyer CH (2011) Enhancing drought tolerance in C4 crops. J Exp Bot 62(9):3135-3153. doi:10.1093/jxb/err105

Mills MJ, Toon OB, Turco RP, Kinnison DE, Garcia RR (2008) Massive global ozone loss predicted following regional nuclear conflict. P Nat Acad Sci 105:5307-5312

National Agricultural Statistics Service (NASS) (2011) Environmental database-http://www.nass.usda.gov/ Statistics_by_Subject/Environmental/index.asp

Oppenheimer C (2003) Climatic, environmental and human consequences of the largest known historic eruption: Tambora volcano (Indonesia) 1815. Prog Phys Geogr 27(2):230-259

Post JD (1977) The last great subsistence crisis in the western world. The Johns Hopkins University Press, Baltimore, p 240

Robock A (1988) Enhancement of surface cooling due to forest fire smoke. Science 242:911-913

Robock A (1991) Surface cooling due to forest fire smoke. J Geophys Res 96:20,869-20,878

Robock A, Oman L, Stenchikov GL, Toon OB, Bardeen C, Turco RP (2007) Climatic consequences of regional nuclear conflicts. Atm Chem Phys 7:2003-2012

Sacks WJ, Kucharik CJ (2011) Trends in crop management and phenology in the U.S. corn belt, and impacts on yields, evapotranspiration, and energy balance. Agric For Meteorol. doi:10.1016/j.agrformet.2011.02.010 
Schmidt GA, Ruedy R, Hansen JE et al (2006) Present-day atmospheric simulations using GISS ModelE: comparison to in situ, satellite, and reanalysis data. J Clim 19:153-192

Sinclair TR (1986) Simulated soya bean production during the recovery phase of a nuclear winter. Agr Ecosyst Environ 17:181-185

Spitters CJT (1986) Separating the diffuse and direct component of global radiation and its implications for modeling canopy photosynthesis Part II. Calculation of canopy photosynthesis. Agr Forest Meteorol 38 (1-3):231-242

Stommel H, Stommel E (1979) The year without a summer. Sci Am 240:176-186

Tollenaar M, Lee EA (2010) Strategies for enhancing grain yield in maize. In: Janick J (ed) Plant breeding reviews, vol 34. John Wiley \& Sons, Inc, Hoboken. doi:10.1002/9780470880579.ch2

Toon OB, Robock A, Turco RP (2008) Environmental consequences of nuclear war. Phys Today 61(12):37-42

Twine TE, Kucharik CJ (2008) Evaluating a terrestrial ecosystem model with satellite information of greenness. J Geophys Res 113:G03027. doi:10.1029/2007JG000599

Xia L, Robock A (2012) Impacts of nuclear war in South Asia on rice production in Mainland China, Climatic Change, this issue 